\title{
Microbial 2-Cys Peroxiredoxins: Insights into Their Complex Physiological Roles
}

\author{
Michel B. Toledano*, and Bo Huang
}

The peroxiredoxins (Prxs) constitute a very large and highly conserved family of thiol-based peroxidases that has been discovered only very recently. We consider here these enzymes through the angle of their discovery, and of some features of their molecular and physiological functions, focusing on complex phenotypes of the gene mutations of the 2-Cys Prxs subtype in yeast. As scavengers of the low levels of $\mathrm{H}_{2} \mathrm{O}_{2}$ and as $\mathrm{H}_{2} \mathrm{O}_{2}$ receptors and transducers, 2-Cys Prxs have been highly instrumental to understand the biological impact of $\mathrm{H}_{2} \mathrm{O}_{2}$, and in particular its signaling function. 2-Cys Prxs can also become potent chaperone holdases, and unveiling the in vivo relevance of this function, which is still not established, should further increase our knowledge of the biological impact and toxicity of $\mathrm{H}_{2} \mathrm{O}_{2}$. The diverse molecular functions of 2-Cys Prx explain the often-hard task of relating them to peroxiredoxin genes phenotypes, which underscores the pleiotropic physiological role of these enzymes and complex biologic impact of $\mathrm{H}_{2} \mathrm{O}_{2}$

\section{INTRODUCTION}

Reactive oxygen species (ROS), which include the superoxide anion $\left(\mathrm{O}_{2}{ }^{--}\right)$, hydrogen peroxide $\left(\mathrm{H}_{2} \mathrm{O}_{2}\right)$ and the hydroxyl radical $\left(\mathrm{HO}^{\circ}\right)$, are produced by the incomplete reduction of oxygen. It is in the fifties that ROS were first proposed to mediate the toxicity of elevated oxygen tension, i.e. poor growth, inflammation, genome instability, loss of cell fitness and cell death, because of their chemical reactivity that is much greater than that of oxygen (Imlay, 2013). The discovery of superoxide dismutase (SOD) by McCord and Fridovich, the enzyme that scavenges $\mathrm{O}_{2}{ }^{-}$(McCord and Fridovich, 1969), in addition to the long known catalases and peroxidases, the enzymes that degrade $\mathrm{H}_{2} \mathrm{O}_{2}$, strongly supported this hypothesis, as indicating that $\mathrm{H}_{2} \mathrm{O}_{2}$ and $\mathrm{O}_{2}{ }^{--}$are not only present in living organism, but must

CEA, DSV, IBITECS, SBIGEM, Laboratoire Stress Oxydant et Cancer (LSOC), CEA-Saclay, 91191 Gif-sur-Yvette, France

*Correspondence: michel.toledano@cea.fr

Received 30 November, 2015; accepted 2 December, 2015; published online 25 January, 2016

Keywords: chaperone, $\mathrm{H}_{2} \mathrm{O}_{2}$ scavenging, $\mathrm{H}_{2} \mathrm{O}_{2}$ signaling, peroxiredoxins be also harmful because enzymes exist to destroy them. However, definite proofs that ROS are the perpetrators of oxygen toxicity came in the eighties with the advent of genetic studies in microorganisms, which showed that disabling ROS scavengers indeed exacerbates the phenotypes of hyperbaric oxygen, thus linking oxygen toxicity to the ROS scavenged by a particular enzyme (Carlioz and Touati, 1986). The peroxiredoxins constitute a very large and highly conserved family of thiol-based peroxidases that has been discovered only very recently, in the nineties. They are bona fide antioxidants that are attracting tremendous attention due to their extra functions in ROS signaling and protein quality control, and to their association with cancer, aging, inflammation and vascular diseases.

We will consider here these enzymes through the angle of their discovery, and of some features of their molecular and physiological functions, focusing on complex phenotypes of the gene mutations of the 2-Cys Prxs subtype in yeast. Echoing the importance of SOD in establishing ROS as culprit of oxygen toxicity, 2-Cys Prxs have been highly instrumental as a tool to understand the biological impact of $\mathrm{H}_{2} \mathrm{O}_{2}$, and in particular its signaling function, and to begin untangling $\mathrm{H}_{2} \mathrm{O}_{2}$ toxicity from its regulatory functions. As we will see, the difficulty that has prevailed in incriminating ROS as the vectors of oxygen toxicity reproduces in the often-hard task of relating peroxiredoxin genes phenotypes to the diverse molecular functions of the encoded enzymes, which underscores the pleiotropic role of these enzymes and the complex biologic impact of $\mathrm{H}_{2} \mathrm{O}_{2}$.

\section{DISCOVERY OF PEROXIREDOXINS}

In 1989, an alkyl hydroperoxide reductase activity was purified from S. typhimurium in Ames's laboratory, based on its ability to reduce the organic peroxide cumene hydroperoxide with $\mathrm{NADH}$ or NADPH as cofactor, but in a manner independent of selenium, glutathione and heme (Jacobson et al., 1989). Two polypeptides made up this activity, a $52-\mathrm{kDa}$ flavoprotein and a $22-$ $\mathrm{kDa}$ protein, named $\mathrm{AhpF}$ and $\mathrm{AhpC}$, respectively. AhpC was proposed to mediate peroxide reduction by a thiol-disulfide based mechanism, and AhpF to couple $\mathrm{NAD}(\mathrm{P}) \mathrm{H}$ oxidation to peroxide reduction by electron transfer between an AhpF redox-active dithiol and the AhpC disulfide.

Concomitantly in Stadtman's lab, Rhee and colleagues purified from yeast extracts a $25-\mathrm{kDa}$ polypeptide that protected glutamine synthase from oxidative inactivation in the presence of a mixed function oxidation system (MFO) $\left(\mathrm{O}_{2}\right.$, iron, and a reducing agent, dithiothreithol or $\beta$-mercaptoethanol) (Kim et al., 
1988), therefore naming it protector protein. MFO generates the highly reactive radical $\mathrm{HO}^{\circ}$, but also reactive sulfur species (RS', RSSR; RSOO') when sulfur is present in the mixture. As the protector protein only afforded protection in the presence of a thiol as reductant, but not ascorbate, its role against a sulfur radical was suspected and the protein was named thiol-specific antioxidant (TSA). Ambiguity regarding the actual enzymatic function of TSA remained however, as the observed strong induction of the TSA-encoding gene (TSA1) by hyperoxia, and the very poor growth of the corresponding null yeast strain to this same condition rather suggested an antioxidant function (Kim et al., 1989). A turn in the story came in the beginning of the nineties, with the advent of gene databases searches, which revealed a high homology between TSA1 and $a h p C$, the genes of the human and Rat TSA at that time identified as retaining protector activity, and with orthologous sequences from diverse organisms from all phyla, thus leading Rhee and colleagues to propose that AhpC and Tsa1 constitute a new family of thiol-based peroxidases (Chae et al., 1994b). The presence of a conserved N-terminal cysteine (Cys) residue in all sequences, and of a C-terminal Cys residue present in most but not all sequences, separated the AhpC/Tsa1 family into 2-Cys and 1-Cys enzymes (Chae et al., 1994b). The Rhee group then renamed Tsa1, thioredoxin peroxidase $(\mathrm{Tpx})$ by analogy with glutathione peroxidase
(Gpx), to acknowledge its true enzymatic function, and on the basis of the purification of thioredoxin and thioredoxin reductase from yeast extracts as the hydrogen donor system of the enzyme peroxidase activity (Chae et al., 1994a), and then as peroxiredoxin (Prx) when it was found that enzymes of the 1Cys group rely on glutathione as hydrogen donor instead of thioredoxin (Chen et al., 2000). The peroxiredoxin enzyme family is since known to scavenge not only $\mathrm{H}_{2} \mathrm{O}_{2}$, but also organic peroxides and is the first enzyme capable of scavenging peroxynitrite (Trujillo et al., 2007).

\section{THE ALTERNATIVE CATALYTIC CYCLES OF 2-CYS PRXS}

The Prx1 subgroup of peroxiredoxins, also known as typical 2Cys Prxs, is the most widespread of the six Prx subfamilies, from archaea, bacteria to eukaryotes (Nelson et al., 2011; Soito et al., 2011). Eukaryotic 2-Cys Prxs share with their prokaryotic counterpart fast catalytic rates $\left(\mathrm{k}_{\mathrm{cat}} / \mathrm{K}_{\mathrm{m}} 10^{7}-10^{8} \mathrm{M}^{-1} \mathrm{~s}^{-1} \sim 10^{7} \mathrm{M}^{-1} \mathrm{~s}^{-1}\right)$ (Parsonage et al., 2008; Peskin et al., 2007), and an extraordinary high reactivity towards peroxides, but are distinguished from them by undergoing inactivation by hyperoxidation at elevated $\mathrm{H}_{2} \mathrm{O}_{2}$ levels (Woo et al., 2003; Wood et al., 2003; Yang et al., 2002). This peculiar attribute individualizes two alternative catalytic cycles, the peroxidatic one and the sulfinic acid one, displayed in Fig. 1.

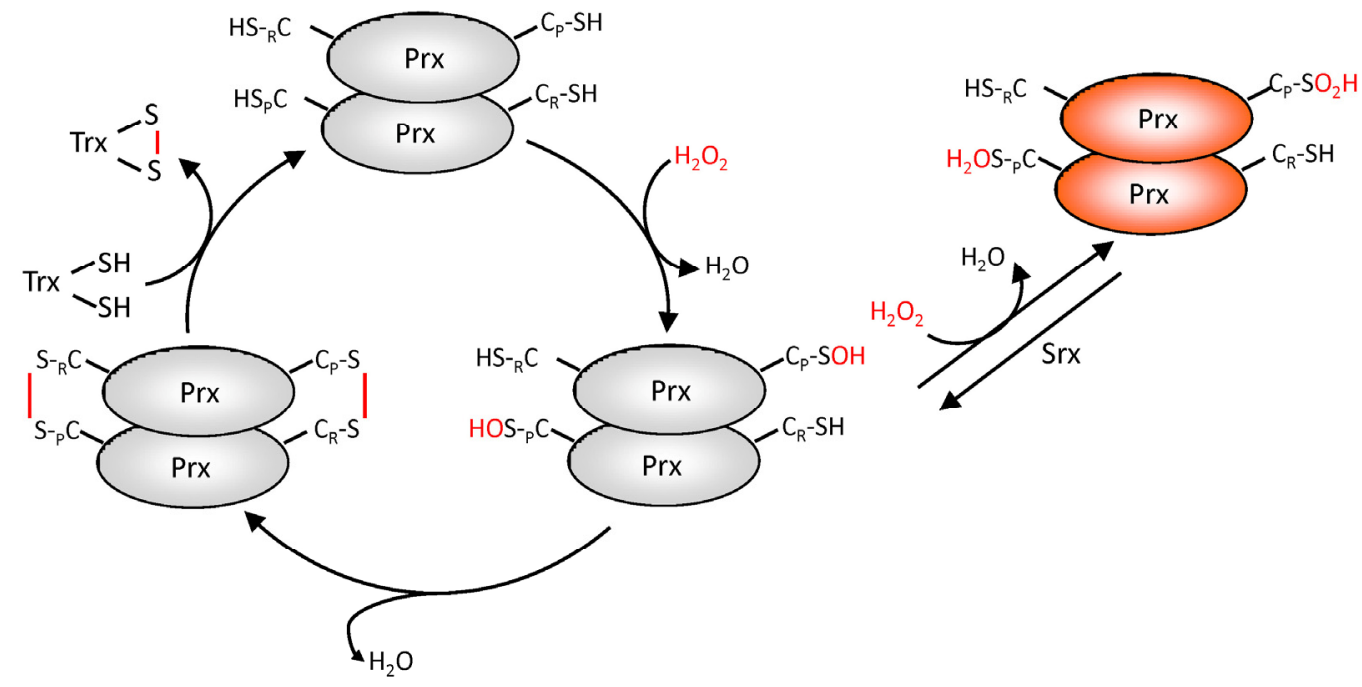

Fig. 1. The two catalytic cycles of 2-Cys Prxs (Noichri et al., 2015). 2-Cys Prx are obligate head-to-tail B-type homodimers, each with two catalytic Cys residues. In the peroxidatic cycle, the $\mathrm{N}$-terminal Cys, named $\mathrm{C}_{\mathrm{p}}$ for peroxidatic Cys, reduces $\mathrm{H}_{2} \mathrm{O}_{2}$ by direct reaction with release of one $\mathrm{H}_{2} \mathrm{O}$ molecule, and is in turn oxidized to a sulfenic acid ( $\mathrm{C}_{\mathrm{P}}-\mathrm{SOH}$ ) (Wood et al., 2003). The Cys-sulfenic acid moiety then condenses with the $\mathrm{C}$-terminal catalytic Cys residue of the other subunit, or resolving $C_{y s}\left(C_{R}\right)$ into an intermolecular disulfide, with release of the second $\mathrm{H}_{2} \mathrm{O}$ molecule. Disulfide formation causes an important structural remodeling both at the $\mathrm{C}_{\mathrm{P}}$-active site pocket and $\mathrm{C}_{\mathrm{R}}$-Containing $\mathrm{C}$-terminal domain, which switches the enzyme structure form a fully folded (FF) to a locally unfolded (LU) conformation (Hall et al., 2011; Wood et al., 2003). Karplus and coworkers have elegantly shown that the enzyme FF conformation both stabilizes the deprotonated reactive form of $C_{P}$ and provides a steric and electrostatic environment that activates $\mathrm{H}_{2} \mathrm{O}_{2}$, hence establishing the observed $C_{p}$ extraordinary high reactivity for $\mathrm{H}_{2} \mathrm{O}_{2}$ (Hall et al., 2010; Karplus, 2015). The catalytic intermolecular disulfide is subsequently reduced by thioredoxin, which completes the catalytic cycle, returning the enzyme to the FF conformation. In the sulfinic acid cycle however, the $\mathrm{C}_{\mathrm{p}} \mathrm{SOH}$ further reacts with $\mathrm{H}_{2} \mathrm{O}_{2}$ instead of condensing with $\mathrm{C}_{R}$, thus becoming oxidized to the corresponding sulfinic acid $\left(-\mathrm{SO}_{2} \mathrm{H}\right)$, which exit the enzyme from the peroxidatic cycle. Sulfinylated Prx undergoes a slow ATP-dependent reduction by the enzyme sulfiredoxin (Srx), which returns the enzyme into the peroxidatic cycle (Biteau et al., 2003; Woo et al., 2003). Sensitivity of eukaryotic enzymes to hyperoxidation is linked to the presence of two sequence fingerprints absent in other family enzymes, an insertion in the loop between $\alpha 4$ and $\beta 5$ carrying the conserved GGLG motif, and an additional helix $(\alpha 7)$ occurring as a C-terminal extension and containing the conserved YF motif (Wood et al., 2003). Such a structural configuration is thought to slow down the FF to LU transition rate, thereby favoring hyperoxidation. 


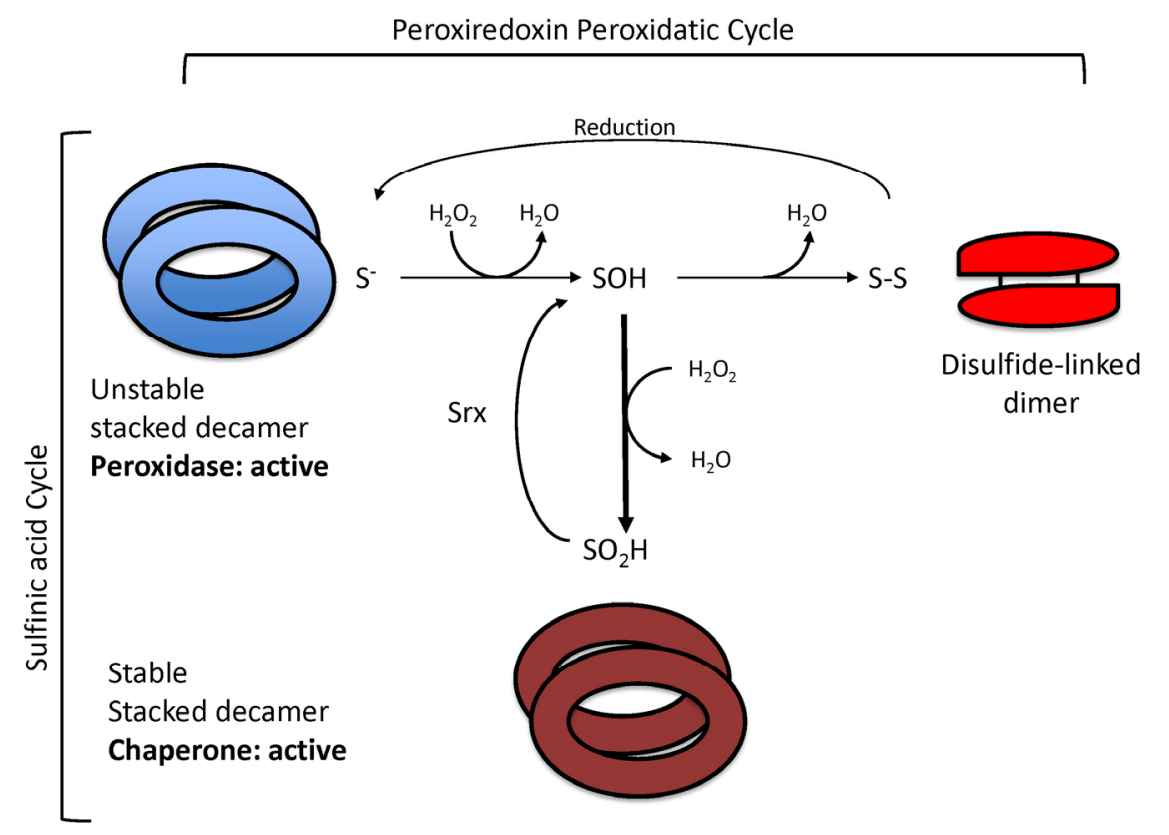

Fig. 2. 2-Cys Prxs enzymatic cycling involves dramatic changes in quaternary structure (Noichri et al., 2015). See the text.

Enzymatic cycling involves dramatic changes in quaternary structure (Fig. 2). Reduced 2-Cys Prxs are typically in the form of decamers arranged in a ring-like toroid structure. During peroxidatic cycling, decamers dissociate into dimers upon disulfide formation, and are regained upon disulfide reduction (Barranco-Medina et al., 2008; 2009; Hall et al., 2011; Parsonage et al., 2005; Sarma et al., 2005; Wood et al., 2002). In contrast, enzyme hyperoxidation stabilize the decameric structure and triggers the stacking of decamers, up to filaments (Cao et al., 2005; Gourlay et al., 2003; Lim et al., 2008; Noichri et al., 2015; Phalen et al., 2006; Saccoccia et al., 2012).

\section{MICROBIAL PEROXIREDOXINS ARE PEROXIDE SCAVENGERS THAT EXCEL TOWARDS LOW ENDOGENOUS $\mathrm{H}_{2} \mathrm{O}_{2}$}

Eukaryotic 2-Cys Prxs combine extremely high $\mathrm{H}_{2} \mathrm{O}_{2}$ reaction rates, reflected by very low $K_{m}$ values (Nelson et al., 2008), and the enzyme oxidative inactivation at elevated $\mathrm{H}_{2} \mathrm{O}_{2}$ levels (Cordray et al., 2007; Wood et al., 2003; Yang et al., 2002). Together with usually very high expression levels, these catalytic features should restrict Prxs scavenging activity towards the low metabolically produced $\mathrm{H}_{2} \mathrm{O}_{2}$ levels (Fourquet et al., 2008; Imlay, 2013).

In Escherichia coli, AhpC indeed came out from microbial genetics and physiological studies as the primary scavenger of the low endogenous $\mathrm{H}_{2} \mathrm{O}_{2}$ produced during normal metabolism (Seaver and Imlay, 2001). In E. coli mutants, an aerobic growth defect is only observed upon simultaneously inactivating all three major peroxide scavenging enzymes, AhpC and the two catalases (KatG and KatE), suggesting overlapping functions between AhpC and catalases (Park et al., 2005; Seaver and Imlay, 2001). However, measure of cellular $\mathrm{H}_{2} \mathrm{O}_{2}$ catabolic efficiencies established that while AhpC is very efficient at scavenging $\mathrm{H}_{2} \mathrm{O}_{2}$ at low, but not at high concentration, the reversely is true for the catalases mutant, which fit the distinct catalytic attributes of these enzymes (Imlay, 2013). In addition, OxyR was constitutively active in the ahpC but not the catalases mutant, further indicating the unique role of $A h p C$ in scavenging the low endogenous levels of $\mathrm{H}_{2} \mathrm{O}_{2}$ (Seaver and Imlay, 2001). Although AhpC is now known as a highly efficient $\mathrm{H}_{2} \mathrm{O}_{2}$ scavenger (Parsonage et al., 2008), AhpC was initially named AhpC, based on its ability to reduce organic peroxides in vitro (Jacobson et al., 1989) and on the dissociated peroxide phenotype of the ahpC null mutant, which displayed hypersensitivity only towards organic peroxides, but not towards $\mathrm{H}_{2} \mathrm{O}_{2}$ (Storz et al., 1989). However, this phenotype is a consequence of the constitutive upregulation of the OxyR-target gene KatG, which is active only towards $\mathrm{H}_{2} \mathrm{O}_{2}$, but not organic peroxides (Seaver and Imlay, 2001).

S. cerevisiae has five Prxs, two cytosolic 2-Cys Prxs, Tsa1 and Tsa2, two atypical 2-Cys Prx, Ahp1 that is cytosolic (Lee et al., 1999b) and nTpx that is nuclear, and a mitochondrial 1-Cys mTpx (Fourquet et al., 2008; Park et al., 2000). S cerevisiae also carries three other thiol peroxidases, Gpx1, Gpx2 and Gpx3 (also known as Orp1 and Hyr1), which are thiol-based enzymes and not selenoenzymes and are dependent upon thioredoxin and not glutathione (Avery and Avery, 2001; Delaunay et al., 2002; Inoue et al., 1999; Tanaka et al., 2005). What are the distinctive and overall physiological role of the eight thiol-peroxidases (Tpxs) in peroxide catabolism? Tsa2, a structural and functional duplicate of Tsa1, is not abundant but stress-inducible (Godon et al., 1998; Lee et al., 1999a), and its protective function is controversial (Munhoz and Netto, 2004; Wong et al., 2004). mTPx has a specific protective role towards peroxides produced during respiration, consistent with its localization (Pedrajas et al., 2000). nTpx does not have any known function. Of the Gpxs, although they have all peroxidase activity in vitro (Avery et al., 2004), only the inactivation of Orp1/Gpx3 leads to defective tolerance to $\mathrm{H}_{2} \mathrm{O}_{2}$ and $\mathrm{t}-\mathrm{BOOH}$ (Delaunay et al., 2002), which is a consequence of defective activation of the peroxide-stress-responsive Yap1 transcriptional regulator (see below). The remaining Tpxs, Tsa1 and Ahp1 are in fact the primary peroxide scavengers, as indicated by the peroxideinduced growth inhibition phenotypes of their corresponding null mutants; however, whereas the TSA1 null strain is more sensitive towards $\mathrm{H}_{2} \mathrm{O}_{2}$ than organic peroxide, the reverse is observed with AHP1 (Chae et al., 1994a; Jeong et al., 1999; 
Lee et al., 1999b). The TSA1 null strain ( $\Delta$ tsa1) also displays a high genome instability not shared with the other Tpx mutants (Huang et al., 2003), which indicates that, as AhpC in E. coli, this enzyme has a unique role in scavenging the low levels of endogenous $\mathrm{H}_{2} \mathrm{O}_{2}$. Such a primary role of Tsa1 in genome protection is further emphasized by the synthetic lethal phenotypes observed when combining $\Delta t s a 1$ with null mutations of the genes encoding recombinational or post-replication repair (Huang and Kolodner, 2005). Prx null mutants with simultaneous deletion of TSA1, TSA2, AHP1, nTPX and mTPX are still viable (Wong et al., 2004), as is a mutant lacking all eight $S$. cerevisiae thiol-based peroxidases named $\Delta 8$ (Fomenko et al., 2011). However, reduced fitness and genome instability phenotypes exacerbates in proportion with the number of isotype inactivated, indicating that the other thiol-based peroxidase can substitute Tsa1 in protecting the genome against endogenous $\mathrm{H}_{2} \mathrm{O}_{2}$ toxicity (Fomenko et al., 2011; Kaya et al., 2014; Wong et al., 2004). As a probable consequence of its genomic instability, $\Delta t s a 1$ displays a significantly shorter replicative life span, and this phenotype is also worsened by successive inactivation of the other Tpxs (Fomenko et al., 2011). Further examination of the $\Delta 8$ mutant has recently shown however that it remains viable only by virtue of constitutively overexpressing of both the inner mitochondrial membrane cytochrome $\mathrm{C}$ peroxidase (Ccp1) and Uth1, a gene of unknown function in mitochondrial biogenesis (Kaya et al., 2015). Overexpression of Ccp1 and Uth1 in this strain is the result of the duplication of chromosome $\mathrm{XI}$ that carries these two loci, thus providing an example of adaptive aneuploidy in $\mathrm{H}_{2} \mathrm{O}_{2}$ tolerance. Ccp1, which scavenges $\mathrm{H}_{2} \mathrm{O}_{2}$ using cytochrome $c$ as electron donor, requires a functional respiratory chain, which explains the paradoxical anaerobic lethality of $\Delta 8$ (Kaya et al., 2015). Uth1 overexpression is probably also required for rescue of $\Delta 8$ as a mean of increasing mitochondrial mass, and therefore Ccp1 activity.

\section{FUNGI PEROXIREDOXINS ARE SENSORS AND TRANSDUCERS OF THE $\mathrm{H}_{2} \mathrm{O}_{2}$ SIGNAL}

The 2-Cys $\operatorname{Prx~} \mathrm{H}_{2} \mathrm{O}_{2}$ extraordinary reactivity also endow them the function of sensor and transducer of the $\mathrm{H}_{2} \mathrm{O}_{2}$ signal. This reactivity is such that, with a very few exceptions, no Cys residue other than $\mathrm{C}_{\mathrm{P}}$ might react with $\mathrm{H}_{2} \mathrm{O}_{2}$ at the concentration at which signaling by this molecule occurs. Exceptions to this rule are enzymes such as the glycolytic enzyme glyceradehyde-3phosphate dehydrogenase, the catalytic core of which contains a Cys residue highly sensitive to $\mathrm{H}_{2} \mathrm{O}_{2}$ that contributes to the metabolic adaption to $\mathrm{H}_{2} \mathrm{O}_{2}$ stress (Peralta et al., 2015).

The role of the $S$. cerevisiae thiol peroxidase Orp1 (Gpx3) in the activation of the bZip transcription factor Yap1 constitutes the first description of the $\mathrm{H}_{2} \mathrm{O}_{2}$ sensing and signaling function of these enzymes (Toledano et al., 2004). Yap1, which regulates an $\mathrm{H}_{2} \mathrm{O}_{2}$-inducible transcriptional adaptive response to this oxidant, is activated by oxidation when intracellular $\mathrm{H}_{2} \mathrm{O}_{2}$ levels rise (Delaunay et al., 2000). Orp1 and not Yap1 however is the $\mathrm{H}_{2} \mathrm{O}_{2}$ sensor of the pathway, hence its name as oxidant receptor peroxidase, which initiates a redox relay that leads to the oxidation of Yap1 into its active form (Delaunay et al., 2002). In this relay, Orp1 $\mathrm{C}_{\mathrm{P}}$ forms a sulfenic acid by reaction with $\mathrm{H}_{2} \mathrm{O}_{2}$, which then condenses with one of Yap1 Cys residues into an intermolecular disulfide, then transposed into a Yap1 intramolecular disulfide by a thiol-disulfide exchange reaction between Orp1 $\mathrm{C}_{\mathrm{p}}$ and a second Yap1 Cys residue (Delaunay et al., 2002; Ma et al., 2007). This redox relay also requires the Yap1binding protein Ybp1 (Veal et al., 2003), which somehow helps the redox interaction between Orp1 and Yap1. In yeast strains lacking Ybp1, Tsa1 and not Orp1 operates as oxidant receptor in Yap1 activation by $\mathrm{H}_{2} \mathrm{O}_{2}$ (Ross et al., 2000; Tachibana et al., 2009; Veal et al., 2003). In S. pombe, it is the 2-Cys Prx Tpx1 that initiates the $\mathrm{H}_{2} \mathrm{O}_{2}$ redox relay leading to the activation of the S. pombe Yap1 homologue, Pap1 (Bozonet et al., 2005; Vivancos et al., 2005). It is not clear however, whether Tpx1 directly oxidizes Pap1, or instead oxidizes its reductase thioredoxin, which in turn oxidizes Pap1 (Brown et al., 2013; Calvo et al., 2013). The Pap1 response is unique in being gradually delayed upon increasing $\mathrm{H}_{2} \mathrm{O}_{2}$ levels, as a result of Tpx1 sulfinylation, which transiently shuts off signaling to Pap1 until Tpx1 sulfinic-acid reduction by the MAP kinase Sty1-induced Srx1 (Bozonet et al., 2005; Vivancos et al., 2005). Pap1 inactivation might be required for a build-up of $\mathrm{H}_{2} \mathrm{O}_{2}$ at levels sufficient to switch on Sty1, which regulates a response to $\mathrm{H}_{2} \mathrm{O}_{2}$ that is different from that of Pap1 (Vivancos et al., 2005). In S. pombe, Tpx1 also contributes to the $\mathrm{H}_{2} \mathrm{O}_{2}$-induced activation of the MAP kinase Sty 1 by engaging $C_{P}$ into a disulfide linkage with a Sty1 Cys residue, thereby canceling out an inhibitory effect carried by this residue on Sty1 phosphorylation by the upstream MAPKK Wis1 (Veal et al., 2004).

If indeed $\mathrm{H}_{2} \mathrm{O}_{2}$ requires Orp1, Tsa1 or Tpx1 for regulating adaptive oxidative stress responses, would other cellular $\mathrm{H}_{2} \mathrm{O}_{2}$ responses make similar use of specific receptors? This question was addressed by monitoring the genome-wide response to $\mathrm{H}_{2} \mathrm{O}_{2}$ in the $\Delta 8$ strain that lacks all eight thiolbased peroxidases (see above) (Fomenko et al., 2011). The massive genomic response to $\mathrm{H}_{2} \mathrm{O}_{2}$-about 1000 genes induced and 500 others repressed, was totally abated in $\Delta 8$, irrespective of the concentration of the oxidant and duration of exposure. Hence, at least in $\mathrm{S}$. cerevisiae, $\mathrm{H}_{2} \mathrm{O}_{2}$ never directly reaches its regulatory targets but is instead funneled to them by ways of thiol peroxidase relays. These data further establish the role of thiol peroxidases as receptors/sensors in $\mathrm{H}_{2} \mathrm{O}_{2}$ signaling, which is now also emerging in higher eukaryotes (Sobotta et al., 2015).

\section{MICROBIAL PRXS AS CHAPERONES}

Lee and coworkers showed that hyperoxidation of the $S$. cerevisiae Tsa1 by $\mathrm{H}_{2} \mathrm{O}_{2}$ triggers the polymerization of the enzyme into high molecular weight (HMW) forms, which have lost peroxidase activity, but have acquired the ability to prevent aggregation of heat-denatured model substrates (Jang et al., 2004), a function that fulfills the definition of a chaperone holdase. This switch from a peroxidase to a chaperone is reversed by reduction of Tsa1 by sulfiredoxin (Srx1) (Jang et al., 2004; Moon et al. 2013). A similar chaperone holdase activity was then described for the human cytosolic 2-Cys Prxs, Prdx1 (Jang et al., 2006; Pan et al., 2014; Park et al., 2011) and Prdx2 (Moon et al., 2005), plant chloroplastic 2-Cys Prxs (Konig et al., 2013), S. mansoni 2-Cys Prx SmPrx1 (Angelucci et al., 2013; Saccoccia et al., 2012), L. infantum mitochondrial 2-Cys Prx mTXNPx (Teixeira et al., 2015), H. pilori 2-Cys Prx AhpC (Chuang et al., 2006), cyanobacterial Anabaena PCC7120 2-Cys Prx alr4641 (Banerjee et al., 2015) and P. aeruginosa 2-Cys Prx PaPrx (An et al., 2010). In all these cases but two, available data fit the model of Jang whereby $\mathrm{H}_{2} \mathrm{O}_{2}$-induced $\mathrm{C}_{P}$ hyperoxidation triggers 2-Cys Prx assembly into HMW structures with chaperone activity (Jang et al., 2004; Moon et al., 2013; Noichri et al., 2015). For the A. thaliana chloroplastic 2-Cys Prx, the chaperone function is triggered by $\mathrm{H}_{2} \mathrm{O}_{2}$ and requires $\mathrm{C}_{P}$ sulfinylation, but the chaperone active form of the enzyme is a decamer and not a higher order oligomer (Konig et al., 2013). In contrast to most Prxs, for the Leishmania infantum mitochondrial 2-Cys 


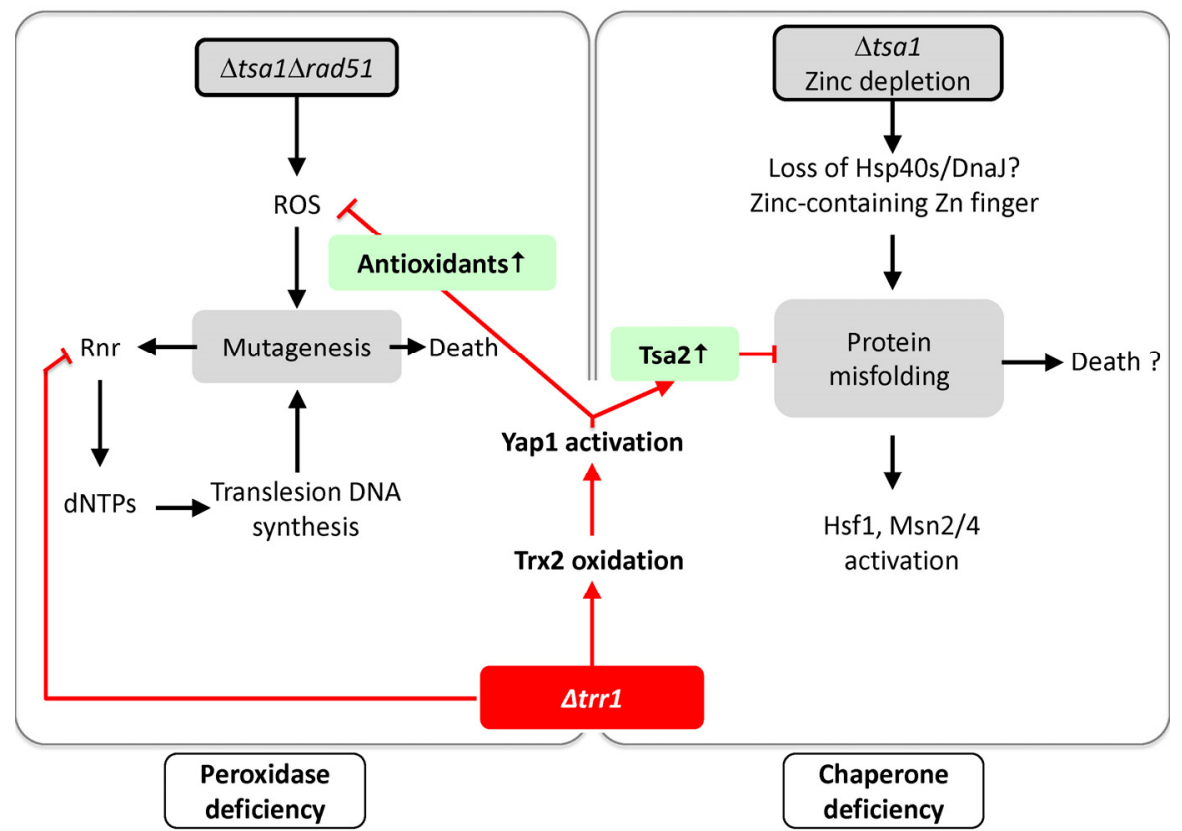

Fig. 3. Loss-of function mutations of cytosolic thioredoxin reductaseencoding TRR1 suppress defects in $\mathrm{H}_{2} \mathrm{O}_{2}$ scavenging and protein quality control linked to the loss of TSA1 (MacDiarmid et al., 2013; Ragu et al., 2014). Suppression is indicated in red arrows (see text).

Prx mTXNPx, activation of the chaperone function is triggered on the reduced decamer by elevated temperature and not $\mathrm{H}_{2} \mathrm{O}_{2}$-induced enzyme hyperoxidation, which leads to major secondary and tertiary structural changes that increase surface hydrophobicity (Castro et al., 2011; Teixeira et al., 2015). As shown by electron microscopy, mTXNPx single decameric rings use direct contacts to position substrates in their ring center. The $L$. infantum case might be akin to the observation of Jang and coworkers that heat treatment can also trigger Tsa1 chaperone activity in a manner independent of $C_{P}$, which suggested that this stress and $\mathrm{H}_{2} \mathrm{O}_{2}$ operate the functional switch of 2-Cys Prx through distinct mechanisms (Jang et al., 2004).

The $L$. infantum mTXNPx is not only unique by the biochemical features of its chaperone function, but also by providing the first example so far of a physiological role of a Prx as a chaperone. L. infantum mTXNPx is indeed essential for host virulence, and for thermotolerance of the insect form of the parasite (Castro et al., 2011). These phenotypes are dependent, not on the enzyme $C_{p}$, thus ruling out the loss of its peroxidase function as causal, but on the enzyme powerful general chaperone function, specifically protecting proteins against temperatureinduced aggregation, and maintaining them in a foldingcompetent conformation (Teixeira et al., 2015). The insect form of the mTXNPx null mutant displayed a substantially higher amount of temperature-induced protein aggregation than its wild type counterpart, thus providing a biochemical signature of the chaperoning role of $\mathrm{mTXNPx}$.

\section{THE COMPLEX PHENOTYPES OF MICROBIAL 2-CYS PRXS}

As carrying the functions of $\mathrm{H}_{2} \mathrm{O}_{2}$ scavengers, $\mathrm{H}_{2} \mathrm{O}_{2}$ signaling devices and chaperones, microbial 2-Cys Prxs necessarily have diverse physiological functions, and not surprisingly their mutation can cause complex phenotypes, as illustrated below.

In the first two studies, loss-of function mutations of cytosolic thioredoxin reductase-encoding TRR1 were selected as suppressors of totally different defects of $\Delta t s a 1$ (MacDiarmid et al.,
2013; Ragu et al., 2014) (Fig. 3). TSA1 is one of several genes induced in zinc-depleted yeast cells and is essential for growth under this condition, a requirement initially interpreted as symptomatic of the presence of oxidative stress caused by zinc depletion (Wu et al., 2007). A selection of transposon-insertion mutations that bypass the requirement of TSA1 upon zinc depletion identified a mutation of the TSA2 promoter that increased its expression by several folds (MacDiarmid et al., 2013). Spontaneous suppressor mutants were also selected, one of which was identified as a loss-of function mutation of TRR1. As the latter condition constitutively activate Yap1 by impairing its reduction, upregulation of the Yap1-target gene TSA2 was invoked as the mechanism of TRR1 suppression. However, as TRR1 is essential for Prx peroxidatic cycling, the idea that Tsa1 is needed to sustain zinc depletion-induced oxidative stress felt. Authors could show instead that Tsa1 is required as a chaperone, based on the following data. They used a Tsa1 resolving Cys residue mutation $\left(C_{R}\right)$, which significantly weakens the enzyme scavenging activity, that fully restored the defective growth of $\Delta t s a 1$ in a zinc-depleted medium. The $\Delta t s a 1$ zinc phenotype was also rescued by overexpression of the chaperones Hsp26 and Hsp42. Lastly, the presence in zinc-depleted $\Delta t s a 1$ of a potent activation of Hsf1 which is usually seen upon cytosolic accumulation of misfolded proteins, and of GFP. Hsp104 foci, which form at sites of protein aggregation, concurred to convince that Tsa1 prevents the accumulation of misfolded proteins upon zinc depletion. How zinc depletion causes protein misfolding and aggregation might be impairing the metallation of the $10 \%$ of cellular zinc-containing proteins, thereby preventing their folding, as suggested by authors.

In the study of Ragu et al. (2014), a TRR1 mutation was selected as a suppressor of a Tsa1-dependent peroxide stress phenotype, in contrast to the previous observation (MacDiarmid et al., 2013) (Fig. 3). As discussed above, $\Delta t s a 1$ is synthetic lethal with RAD51, with other DNA strand break repair genes and RAD6 (Huang and Kolodner, 2005; Smith et al., 2004). This synthetic lethality is a consequence of $\mathrm{H}_{2} \mathrm{O}_{2}$ genome toxicity, as rescued by anaerobiosis (Ragu et al., 2007), and is due to the combined loss of the major endogenous $\mathrm{H}_{2} \mathrm{O}_{2}$ scavenger 
and a major DNA repair enzyme. Upregulation of Yap1 was also invoked as the trr1 suppression mechanism, as improving peroxide scavenging through increased expression of its target genes that comprise most yeast reductases and scavenging activities. In this case however, TSA2 was dispensable for suppression, in keeping with the notion that anyhow it would be inactive in the trr1 mutant (Ragu et al., 2014). A second suppression mechanism was also suggested however. Through the activation of checkpoint pathways, $\mathrm{H}_{2} \mathrm{O}_{2}$-induced DNA damage stimulates the production of dNTPs needed for DNA repair (Chabes et al., 2003), which also paradoxically increases mutation rates by more efficient translesion DNA synthesis (Sabouri et al., 2008). A vicious circle between the accumulation of DNA lesions and the chronic activation of checkpoint pathways was invoked to explain the abnormally high mutagenesis rate of $\Delta t s a 1$ (Tang et al., 2009). As dNTP synthesis involves the thioredoxin-dependent redox cycling of ribonucleotide reductase, inactivation of Trr1 also rescued the $\Delta t s a 1 \Delta$ rad51 lethal phenotype by decreasing this synthesis (Ragu et al., 2014).

A role of Tsa1 in preventing protein damage was recently shown, but this effect was shown to involve its peroxidase and not chaperone function (Weids and Grant, 2014). In this study, $\Delta t s a 1$ was shown to be highly sensitive to the proline analogue azetidine-2-carboxylic acid (AZC), which causes nascentprotein misfolding and aggregation. Hypersensitivity was seen under aerobiosis, but not anaerobiosis, and was totally rescued by the loss of mitochondrial DNA, which led authors to conclude that the protein aggregates induced by AZC cause the toxic mitochondrial production of $\mathrm{H}_{2} \mathrm{O}_{2}$, and Tsa1 prevent this toxicity by scavenging $\mathrm{H}_{2} \mathrm{O}_{2}$.

Deletion of TSA1 was also shown to worsen the growth defect and the accumulation of carbonylated proteins resulting from inactivation of the vacuolar iron transporter Ccc1, which lead to cytosolic accumulation of iron (Lin et al., 2011). Exacerbation of the iron toxicity of $\Delta \mathrm{cc} 1$ by the deletion of TSA 1 was seen both under aerobiosis and anaerobiosis, which led these authors unable to decide between the peroxidase or chaperone function of Tsa1 as important in this setting.

The last study considered, which describes a novel function of TSA1 and SRX1 in yeast replicative aging, also opens the question of which is the function of Tsa1 that underlies a given TSA1 phenotype (Molin et al., 2011). In this study, the ability of caloric restriction to increase yeast replicative lifespan was shown to be lost in strains lacking either SRX1 or TSA1, therefore establishing these two genes products as effectors or facilitators of the effects of $\mathrm{CR}$ on replicative aging. Furthermore, increasing the expression of $S R X 1$ in the absence of CR also increased life span by about $20 \%$, but in the presence and not the absence of TSA1, thus indicating that Srx1 and Tsa1 have a linked function in aging. The nutrient sensitive CAMP-PKA pathway was established as the link between CR and Tsa1 and Srx1, as this pathway, which is downregulated by CR, was shown to repress Tsa1 and Srx1 expression by imposing a translation block involving the activation of the elF2 kinase Gcn2 (Molin et al., 2011).

\section{FAILURE OF GENETICS IN LINKING 2-CYS PRX MOLECULAR FUNCTIONS AND PHENOTYPES}

When trying to link phenotypes and molecular functions, it is easy to ascribe the genomic instability to defective Prx scavenging, and alterations of $\mathrm{H}_{2} \mathrm{O}_{2}$ genomic responses and tolerance to the loss of Prx-dependent $\mathrm{H}_{2} \mathrm{O}_{2}$ signaling. However, as illustrated by the studies considered above, it is not as easy to ascribe a given phenotype to the alteration of Prx chaperone function, and in other cases to elucidate the process responsible for a given phenotype. The demonstrated role of the $L$. infantum mTXNPx in protein quality control (PQC) and its importance for parasite virulence is compelling, and perhaps the unique example so far of a chaperoning function for a peroxiredoxin (Texeira et al., 2015). The requirement of Tsa1 as a chaperone for yeast growth under zinc depletion also provide some good evidence of this function (MacDiarmid et al., 2013), still how to explain this requirement in view of the very numerous and efficient chaperone systems that already exist in the cytosol of an eukaryotic cell? One possible answer could be, as suggested by authors, that the other PQC systems become disabled as a consequence of loss of the zinc-finger-containing DnaJ enzymes, which activate Hsp70 ATPase activity and contribute with the latter to the recognition of folding substrates. Accordingly, 2-Cys Prxs would backup PQC systems, only becoming important under the physiological conditions that mimic zinc depletion. Conversely, the CCP1 rescue of the now known unviable phenotype of the yeast $\Delta 8$ strain, which lacks all yeast thiol peroxidases (Fomenko et al., 2015), indicates that these enzymes essential nature is linked to their scavenging functions. Accordingly, the $\Delta 8$ strain-oxygen auxotrophy is the consequence of the respiratory chain requirement for Ccp1 activity. However, if these enzymes are indeed essential as $\mathrm{H}_{2} \mathrm{O}_{2}$ scavengers, why then is $\Delta 8$ not viable under anaerobiosis a condition that should lower if not abate $\mathrm{H}_{2} \mathrm{O}_{2}$-dependent phenotypes? In the absence of $\mathrm{H}_{2} \mathrm{O}_{2}$, the 2-Cys Prx redox relay function cannot be invoked, but what about the chaperone function, and why then under anaerobiosis? By linking CR restriction-induced replicative life span extension to the role of Tsa1 and $\mathrm{Srx} 1$ in $\mathrm{H}_{2} \mathrm{O}_{2}$ resistance, the study of Molin apparently indicated that Tsa1/Srx1 affect lifespan as peroxide scavengers (Molin et al., 2011). However, this linkage was only correlative, and Tsa1 and Srx1 could also influence lifespan as a chaperone. One could even ask whether 2-Cys Prx contributes to $\mathrm{H}_{2} \mathrm{O}_{2}$ stress resistance as chaperones. Similarly in the study of Lin et al. (2011), authors could not conclude as to which of the function of Tsa1 is preventing iron toxicity. The difficulty in linking molecular functions and phenotypes resides in the intertwined nature 2-Cys Prx peroxidase and chaperone functions, and hence in the lack of mutations that could unambiguously separate them. Except for the $L$. infantum mTXNPx, the 2-Cys Prx $\mathrm{C}_{\mathrm{P}}$ is essential both for $\mathrm{H}_{2} \mathrm{O}_{2}$ scavenging and for chaperoning. Weids and Grant (2014) and Lin et al. (2011) used the $C_{P}$ mutation-induced loss of Tsa1 peroxidase activity to establish the importance of this function in preventing AZC and iron toxicity, respectively, which is fair in view of the lack of robust data regarding the absolute requirement of $C_{P}$ for chaperoning. Mutation of the 2-Cys resolving Cys $C_{R}$ has been used by Molin et al. (2011) and MacDiarmid et al. (2013), to disable scavenging without hampering chaperoning, based on the known effect of this mutation to weaken scavenging, but whether it also alters chaperoning is not known, due to very limited knowledge of the molecular details of this function.

\section{CONCLUSION}

Studies of the bacterial and yeast 2-Cys Prxs have clearly established a primary role of these enzymes in scavenging the low levels of $\mathrm{H}_{2} \mathrm{O}_{2}$ produced during normal growth, and their inefficiency in the face of $\mathrm{H}_{2} \mathrm{O}_{2}$ onslaughts, which fit their in vitro peroxidase function and its catalytic features, in particular their extraordinary $\mathrm{H}_{2} \mathrm{O}_{2}$ reactivity. They have also revealed the role of 2-Cys Prx, and more generally of thiol peroxidases, as re- 
ceptors and transducers of the $\mathrm{H}_{2} \mathrm{O}_{2}$ signal, a function conserved in mammals (Sabotta MC et al., 2014), which is also based on these enzymes high $\mathrm{H}_{2} \mathrm{O}_{2}$ reactivity. Lastly they indicate that 2-Cys Prxs can become potent chaperone holdases, but apart a few exceptions, knowledge of this function is mainly based on in vitro data, and so far not a hint of an in vivo molecular function, of potential substrates and physiological scope is yet available. Furthermore, as we just saw above, establishing which of the 2-Cys Prx molecular function(s) underlie their physiological action in aging and PQC remains a difficult task, leading sometimes to ambiguous answers. Such ambiguity is reminiscent of the one that prevailed in the old days in establishing the role of ROS as the culprit of oxygen toxicity and antioxidants as ROS scavengers and in the discovery of Tsa1 by Rhee and colleagues (Chae et al., 1988). This ambiguity can lead to the provocative question of whether Tsa1 was identified based on its chaperone activity, rather than on its scavenging function, by protecting glutamine synthase from oxidative damage by $\mathrm{HO}^{\circ}$. Rhee ruled out this possibility, based on the Tsa1 protective effect seen only in the presence of a thiol donor in the MFO system (DTT, thioredoxin), but not in the presence of ascorbate, which was taken as a proof of the requirement of Tsa1 peroxidatic cycling. However peroxidatic cycling is part of the chaperone activation process, which requires, at least in some cases $\mathrm{C}_{\mathrm{P}}$ hyperoxidation.

It will thus be important in the future to establish biochemical signatures of the 2-Cys Prx chaperone function, and growth conditions that require this function. It will be also important to address the 2-Cys Prx structure-chaperone function relationship, which will help design mutations that non ambiguously separate this function from the enzyme peroxidase function.

\section{ACKNOWLEDGMENTS}

This work was funded by grant from ANR ERRed and InCA PLBIO INCA_5869 to MBT, and CEA/Marie Curie Enhanced Eurotalents fellowship to $\mathrm{BH}$.

\section{REFERENCES}

An, B.C., Lee, S.S., Lee, E.M., Lee, J.T., Wi, S.G., Jung, H.S., Park W., and Chung, B.Y. (2010). A new antioxidant with dual functions as a peroxidase and chaperone in Pseudomonas aeruginosa. Mo. Cells 29, 145-151.

Angelucci, F., Saccoccia, F., Ardini, M., Boumis, G., Brunori, M., Di Leandro, L., Ippoliti, R., Miele, A.E., Natoli, G., Scotti, S., et al. (2013). Switching between the alternative structures and functions of a 2-Cys peroxiredoxin, by site-directed mutagenesis. J. Mol. Biol. 425, 4556-4568.

Avery, A.M., and Avery, S.V. (2001). Saccharomyces cerevisiae expresses three phospholipid hydroperoxide glutathione peroxidases. J. Biol. Chem. 276, 33730-33735.

Avery, A.M., Willetts, S.A., and Avery, S.V. (2004). Genetic dissection of the phospholipid hydroperoxidase activity of yeast gpx3 reveals its functional importance. J. Biol. Chem. 279, 46652-46658.

Banerjee, M., Chakravarty, D., and Ballal, A. (2015). Redoxdependent chaperone/peroxidase function of 2-Cys-Prx from the cyanobacterium Anabaena PCC7120: role in oxidative stress tolerance. BMC Plant Biol. 15, 60.

Barranco-Medina, S., Kakorin, S., Lazaro, J.J., and Dietz, K.J. (2008). Thermodynamics of the dimer-decamer transition of reduced human and plant 2-cys peroxiredoxin. Biochemistry 47 , 7196-7204.

Barranco-Medina, S., Lazaro, J.J., and Dietz, K.J. (2009). The oligomeric conformation of peroxiredoxins links redox state to function. FEBS Lett. 583, 1809-1816.

Biteau, B., Labarre, J., and Toledano, M.B. (2003). ATP-dependent reduction of cysteine-sulphinic acid by $\mathrm{S}$. cerevisiae sulphiredoxin. Nature 425, 980-984.
Bozonet, S.M., Findlay, V.J., Day, A.M., Cameron, J., Veal, E.A., and Morgan, B.A. (2005). Oxidation of a eukaryotic 2-Cys peroxiredoxin is a molecular switch controlling the transcriptional response to increasing levels of hydrogen peroxide. J. Biol. Chem. 280, 23319-23327.

Brown, J.D., Day, A.M., Taylor, S.R., Tomalin, L.E., Morgan, B.A., and Veal, E.A. (2013). A peroxiredoxin promotes $\mathrm{H} 2 \mathrm{O} 2$ signaling and oxidative stress resistance by oxidizing a thioredoxin family protein. Cell Rep. 5, 1425-1435.

Calvo, I.A., Boronat, S., Domenech, A., Garcia-Santamarina, S., Ayte, J., and Hidalgo, E. (2013). Dissection of a redox relay: $\mathrm{H} 2 \mathrm{O} 2-$ dependent activation of the transcription factor Pap1 through the peroxidatic Tpx1-thioredoxin cycle. Cell Rep. 5, 1413-1424.

Cao, Z., Roszak, A.W., Gourlay, L.J., Lindsay, J.G., and Isaacs, N.W. (2005). Bovine mitochondrial peroxiredoxin III forms a two-ring catenane. Structure 13, 1661-1664.

Carlioz, A., and Touati, D. (1986). Isolation of superoxide dismutase mutants in Escherichia coli: is superoxide dismutase necessary for aerobic life? EMBO J. 5, 623-630.

Castro, H., Teixeira, F., Romao, S., Santos, M., Cruz, T., Florido, M., Appelberg, R., Oliveira, P., Ferreira-da-Silva, F., and Tomas, A.M (2011). Leishmania mitochondrial peroxiredoxin plays a crucial peroxidase-unrelated role during infection: insight into its novel chaperone activity. PLoS Pathogens 7, e1002325.

Chabes, A., Georgieva, B., Domkin, V., Zhao, X., Rothstein, R., and Thelander, L. (2003). Survival of DNA damage in yeast directly depends on increased dNTP levels allowed by relaxed feedback inhibition of ribonucleotide reductase. Cell 112, 391-401.

Chae, H.Z., Chung, S.J., and Rhee, S.G. (1994a). Thioredoxindependent peroxide reductase from yeast. J. Biol. Chem. 269 27670-27678.

Chae, H.Z., Robison, K., Poole, L.B., Church, G., Storz, G., and Rhee, S.G. (1994b). Cloning and sequencing of thiol-specific antioxidant from mammalian brain: alkyl hydroperoxide reductase and thiol-specific antioxidant define a large family of antioxidant enzymes. Proc. Natl. Acad. Sci. USA 91, 7017-7021.

Chen, J.W., Dodia, C., Feinstein, S.I., Jain, M.K., and Fisher, A.B. (2000). 1-Cys peroxiredoxin, a bifunctional enzyme with glutathione peroxidase and phospholipase A2 activities. J. Biol. Chem. 275, 28421-28427.

Chuang, M.H., Wu, M.S., Lo, W.L., Lin, J.T., Wong, C.H., and Chiou, S.H. (2006). The antioxidant protein alkylhydroperoxide reductase of Helicobacter pylori switches from a peroxide reductase to a molecular chaperone function. Proc. Natl. Acad. Sci. USA 103, 2552-2557.

Cordray, P., Doyle, K., Edes, K., Moos, P.J., and Fitzpatrick, F.A. (2007). Oxidation of 2-Cys-peroxiredoxins by arachidonic acid peroxide metabolites of lipoxygenases and cyclooxygenase-2. J. Biol. Chem. 282, 32623-32629.

Delaunay, A., Isnard, A.D., and Toledano, M.B. (2000). H2O2 sensing through oxidation of the Yap1 transcription factor. EMBO J. 19, 5157-5166.

Delaunay, A., Pflieger, D., Barrault, M.B., Vinh, J., and Toledano, M.B. (2002). A thiol peroxidase is an $\mathrm{H} 2 \mathrm{O} 2$ receptor and redoxtransducer in gene activation. Cell 111, 471-481.

Fomenko, D.E., Koc, A., Agisheva, N., Jacobsen, M., Kaya, A., Malinouski, M., Rutherford, J.C., Siu, K.L., Jin, D.Y., Winge, D.R., et al. (2011). Thiol peroxidases mediate specific genome-wide regulation of gene expression in response to hydrogen peroxide. Proc. Natl. Acad. Sci. USA 108, 2729-2734.

Fourquet, S., Huang, M.E., D'Autreaux, B., and Toledano, M.B. (2008). The dual functions of thiol-based peroxidases in $\mathrm{H} 2 \mathrm{O} 2$ scavenging and signaling. Antioxid. Redox Signal. 10, 15651576.

Godon, C., Lagniel, G., Lee, J., Buhler, J.M., Kieffer, S., Perrot, M., Boucherie, H., Toledano, M.B., and Labarre, J. (1998). The $\mathrm{H} 2 \mathrm{O} 2$ stimulon in Saccharomyces cerevisiae. J. Biol. Chem. 273, 22480-22489.

Gourlay, L.J., Bhella, D., Kelly, S.M., Price, N.C., and Lindsay, J.G. (2003). Structure-function analysis of recombinant substrate protein $22 \mathrm{kDa}$ (SP-22). A mitochondrial 2-CYS peroxiredoxin organized as a decameric toroid. J. Biol. Chem. 278, 3263132637.

Hall, A., Parsonage, D., Poole, L.B., and Karplus, P.A. (2010). Structural evidence that peroxiredoxin catalytic power is based 
on transition-state stabilization. J. Mol. Biol. 402, 194-209.

Hall, A., Nelson, K., Poole, L.B., and Karplus, P.A. (2011). Structurebased insights into the catalytic power and conformational dexterity of peroxiredoxins. Antioxid. Redox Signal. 15, 795-815.

Huang, M.E., Rio, A.G., Nicolas, A., and Kolodner, R.D. (2003). A genomewide screen in Saccharomyces cerevisiae for genes that suppress the accumulation of mutations. Proc. Natl. Acad. Sci. USA 100, 11529-11534.

Huang, M.E., and Kolodner, R.D. (2005). A biological network in Saccharomyces cerevisiae prevents the deleterious effects of endogenous oxidative DNA damage. Mol. Cell 17, 709-720.

Imlay, J.A. (2013). The molecular mechanisms and physiological consequences of oxidative stress: lessons from a model bacterium. Nat. Rev. Microbiol. 11, 443-454.

Inoue, Y., Matsuda, T., Sugiyama, K., Izawa, S., and Kimura, A. (1999). Genetic analysis of glutathione peroxidase in oxidative stress response of Saccharomyces cerevisiae. J. Biol. Chem. 274, 27002-27009.

Jacobson, F.S., Morgan, R.W., Christman, M.F., and Ames, B.N (1989). An alkyl hydroperoxide reductase from Salmonella typhimurium involved in the defense of DNA against oxidative damage. Purification and properties. J. Biol. Chem. 264, 14881496.

Jang, H.H., Lee, K.O., Chi, Y.H., Jung, B.G., Park, S.K., Park, J.H., Lee, J.R., Lee, S.S., Moon, J.C., Yun, J.W., et al. (2004). Two enzymes in one; two yeast peroxiredoxins display oxidative stress-dependent switching from a peroxidase to a molecular chaperone function. Cell 117, 625-635.

Jang, H.H., Kim, S.Y., Park, S.K., Jeon, H.S., Lee, Y.M., Jung, J.H., Lee, S.Y., Chae, H.B., Jung, Y.J., Lee, K.O., et al. (2006) Phosphorylation and concomitant structural changes in human 2-Cys peroxiredoxin isotype I differentially regulate its peroxidase and molecular chaperone functions. FEBS Lett. 580, 351-355.

Jeong, J.S., Kwon, S.J., Kang, S.W., Rhee, S.G., and Kim, K. (1999). Purification and characterization of a second type thioredoxin peroxidase (type II TPx) from Saccharomyces cerevisiae. Biochemistry 38, 776-783.

Karplus, P.A. (2015). A primer on peroxiredoxin biochemistry. Free Radic. Biol. Med. 80, 183-190.

Kaya, A., Lobanov, A.V., Gerashchenko, M.V., Koren, A., Fomenko, D.E., Koc, A., and Gladyshev, V.N. (2014). Thiol peroxidase deficiency leads to increased mutational load and decreased fitness in Saccharomyces cerevisiae. Genetics 198, 905-917.

Kaya, A., Gerashchenko, M.V., Seim, I., Labarre, J., Toledano, M.B., and Gladyshev, V.N. (2015). Adaptive aneuploidy protects against thiol peroxidase deficiency by increasing respiration via key mitochondrial proteins. Proc. Natl. Acad. Sci. USA 112, 10685-10690.

Kim, K., Kim, I.H., Lee, K.Y., Rhee, S.G., and Stadtman, E.R. (1988). The isolation and purification of a specific "protector" protein which inhibits enzyme inactivation by a thiol/Fe(III)/O2 mixedfunction oxidation system. J. Biol. Chem. 263, 4704-4711.

Kim, I.H., Kim, K., and Rhee, S.G. (1989). Induction of an antioxidant protein of Saccharomyces cerevisiae by $\mathrm{O} 2, \mathrm{Fe} 3+$, or 2-mercaptoethanol. Proc. Natl. Acad. Sci. USA 86, 6018-6022.

Konig, J., Galliardt, H., Jutte, P., Schaper, S., Dittmann, L., and Dietz, K.J. (2013). The conformational bases for the two functionalities of 2-cysteine peroxiredoxins as peroxidase and chaperone. J. Exp. Bot. 64, 3483-3497.

Lee, J., Godon, C., Lagniel, G., Spector, D., Garin, J., Labarre, J., and Toledano, M.B. (1999a). Yap1 and Skn7 control two specialized oxidative stress response regulons in yeast. J. Biol. Chem. 274, 16040-16046.

Lee, J., Spector, D., Godon, C., Labarre, J., and Toledano, M.B. (1999b). A new antioxidant with alkyl hydroperoxide defense properties in yeast. J. Biol. Chem. 274, 4537-4544.

Lim, J.C., Choi, H.I., Park, Y.S., Nam, H.W., Woo, H.A., Kwon, K.S., Kim, Y.S., Rhee, S.G., Kim, K., and Chae, H.Z. (2008). Irreversible oxidation of the active-site cysteine of peroxiredoxin to cysteine sulfonic acid for enhanced molecular chaperone activity. J. Biol. Chem. 283, 28873-28880.

Lin, H., Li, L., Jia, X., Ward, D.M., and Kaplan, J. (2011). Genetic and biochemical analysis of high iron toxicity in yeast: iron toxicity is due to the accumulation of cytosolic iron and occurs under both aerobic and anaerobic conditions. J. Biol. Chem. 286 ,
3851-3862.

Ma, L.H., Takanishi, C.L., and Wood, M.J. (2007). Molecular mechanism of oxidative stress perception by the Orp1 protein. J. Biol. Chem. 282, 31429-31436.

MacDiarmid, C.W., Taggart, J., Kerdsomboon, K., Kubisiak, M., Panascharoen, S., Schelble, K., and Eide, D.J. (2013). Peroxiredoxin chaperone activity is critical for protein homeostasis in zinc-deficient yeast. J. Biol. Chem. 288, 3131331327.

McCord, J.M., and Fridovich, I. (1969). The utility of superoxide dismutase in studying free radical reactions. I. Radicals generated by the interaction of sulfite, dimethyl sulfoxide, and oxygen. J. Biol. Chem. 244, 6056-6063.

Molin, M., Yang, J., Hanzen, S., Toledano, M.B., Labarre, J., and Nystrom, T. (2011). Life span extension and $\mathrm{H}(2) \mathrm{O}(2)$ resistance elicited by caloric restriction require the peroxiredoxin Tsa1 in Saccharomyces cerevisiae. Mol. Cell 43, 823-833.

Moon, J.C., Hah, Y.S., Kim, W.Y., Jung, B.G., Jang, H.H., Lee, J.R., Kim, S.Y., Lee, Y.M., Jeon, M.G., Kim, C.W., et al. (2005) Oxidative stress-dependent structural and functional switching of a human 2-Cys peroxiredoxin isotype II that enhances HeLa cell resistance to $\mathrm{H} 2 \mathrm{O} 2$-induced cell death. J. Biol. Chem. 280 , 28775-28784.

Moon, J.C., Kim, G.M., Kim, E.K., Lee, H.N., Ha, B., Lee, S.Y., and Jang, H.H. (2013). Reversal of 2-Cys peroxiredoxin oligomerization by sulfiredoxin. Biochem. Biophys. Res. Commun. 432, 291-295.

Munhoz, D.C., and Netto, L.E. (2004). Cytosolic thioredoxin peroxidase I and II are important defenses of yeast against organic hydroperoxide insult: catalases and peroxiredoxins cooperate in the decomposition of $\mathrm{H} 2 \mathrm{O} 2$ by yeast. J. Biol. Chem. 279, 35219-35227

Nelson, K.J., Parsonage, D., Hall, A., Karplus, P.A., and Poole, L.B. (2008). Cysteine pK(a) values for the bacterial peroxiredoxin AhpC. Biochemistry 47, 12860-12868.

Nelson, K.J., Knutson, S.T., Soito, L., Klomsiri, C., Poole, L.B., and Fetrow, J.S. (2011). Analysis of the peroxiredoxin family: using active-site structure and sequence information for global classification and residue analysis. Proteins 79, 947-964.

Noichri, Y., Palais, G., Ruby, V., D'Autreaux, B., Delaunay-Moisan, A., Nystrom, T., Molin, M., and Toledano, M.B. (2015). In vivo parameters influencing 2-Cys Prx oligomerization: The role of enzyme sulfinylation. Redox. Biol. 6, 326-333.

Pan, Y., Jin, J.H., Yu, Y., and Wang, J. (2014). Significant enhancement of hPrx1 chaperone activity through lysine acetylation. Chembiochem 15, 1773-1776.

Park, S.G., Cha, M.K., Jeong, W., and Kim, I.H. (2000). Distinct physiological functions of thiol peroxidase isoenzymes in Saccharomyces cerevisiae. J. Biol. Chem. 275, 5723-5732.

Park, S., You, X., and Imlay, J.A. (2005). Substantial DNA damage from submicromolar intracellular hydrogen peroxide detected in Hpx- mutants of Escherichia coli. Proc. Natl. Acad. Sci. USA 102 9317-9322

Park, J.W., Piszczek, G., Rhee, S.G., and Chock, P.B. (2011). Glutathionylation of peroxiredoxin I induces decamer to dimers dissociation with concomitant loss of chaperone activity. Biochemistry 50, 3204-3210.

Parsonage, D., Youngblood, D.S., Sarma, G.N., Wood, Z.A. Karplus, P.A., and Poole, L.B. (2005). Analysis of the link between enzymatic activity and oligomeric state in AhpC, a bacterial peroxiredoxin. Biochemistry 44, 10583-10592.

Parsonage, D., Karplus, P.A., and Poole, L.B. (2008). Substrate specificity and redox potential of AhpC, a bacterial peroxiredoxin Proc. Natl. Acad. Sci. USA 105, 8209-8214.

Pedrajas, J.R., Miranda-Vizuete, A., Javanmardy, N., Gustafsson, J.A., and Spyrou, G. (2000). Mitochondria of Saccharomyces cerevisiae contain one-conserved cysteine type peroxiredoxin with thioredoxin peroxidase activity. J. Biol. Chem. 275, 1629616301

Peralta, D., Bronowska, A.K., Morgan, B., Doka, E., Van Laer, K., Nagy, P., Grater, F., and Dick, T.P. (2015). A proton relay enhances $\mathrm{H} 2 \mathrm{O} 2$ sensitivity of GAPDH to facilitate metabolic adaptation. Nat. Chem. Biol. 11, 156-163.

Peskin, A.V., Low, F.M., Paton, L.N., Maghzal, G.J., Hampton, M.B., and Winterbourn, C.C. (2007). The high reactivity of peroxiredoxin 2 with $\mathrm{H}(2) \mathrm{O}(2)$ is not reflected in its reaction with 
other oxidants and thiol reagents. J. Biol. Chem. 282, 1188511892.

Phalen, T.J., Weirather, K., Deming, P.B., Anathy, V., Howe, A.K., van der Vliet, A., Jonsson, T.J., Poole, L.B., and Heintz, N.H. (2006). Oxidation state governs structural transitions in peroxiredoxin II that correlate with cell cycle arrest and recovery. J. Cell Biol. 175, 779-789.

Ragu, S., Faye, G., Iraqui, I., Masurel-Heneman, A., Kolodner, R.D., and Huang, M.E. (2007). Oxygen metabolism and reactive oxygen species cause chromosomal rearrangements and cell death. Proc. Natl. Acad. Sci. USA 104, 9747-9752.

Ragu, S., Dardalhon, M., Sharma, S., Iraqui, I., BuhagiarLabarchede, G., Grondin, V., Kienda, G., Vernis, L., Chanet, R., Kolodner, R.D., et al. (2014). Loss of the thioredoxin reductase Trr1 suppresses the genomic instability of peroxiredoxin tsa1 mutants. PLoS One 9, e108123.

Ross, S.J., Findlay, V.J., Malakasi, P., and Morgan, B.A. (2000). Thioredoxin peroxidase is required for the transcriptional response to oxidative stress in budding yeast. Mol. Biol. Cell 11, 2631-2642.

Sabouri, N., Viberg, J., Goyal, D.K., Johansson, E., and Chabes, A. (2008). Evidence for lesion bypass by yeast replicative DNA polymerases during DNA damage. Nucleic Acids Res. 36, 56605667.

Saccoccia, F., Di Micco, P., Boumis, G., Brunori, M., Koutris, I., Miele, A.E., Morea, V., Sriratana, P., Williams, D.L., Bellelli, A., et al. (2012). Moonlighting by different stressors: crystal structure of the chaperone species of a 2-Cys peroxiredoxin. Structure 20, 429-439.

Sarma, G.N., Nickel, C., Rahlfs, S., Fischer, M., Becker, K., and Karplus, P.A. (2005). Crystal structure of a novel Plasmodium falciparum 1-Cys peroxiredoxin. J. Mol. Biol. 346, 1021-1034.

Seaver, L.C., and Imlay, J.A. (2001). Alkyl hydroperoxide reductase is the primary scavenger of endogenous hydrogen peroxide in Escherichia coli. J. Bacteriol. 183, 7173-7181.

Smith, S., Hwang, J.Y., Banerjee, S., Majeed, A., Gupta, A., and Myung, K. (2004). Mutator genes for suppression of gross chromosomal rearrangements identified by a genome-wide screening in Saccharomyces cerevisiae. Proc. Natl. Acad. Sci. USA 101, 9039-9044.

Sobotta, M.C., Liou, W., Stocker, S., Talwar, D., Oehler, M., Ruppert, T., Scharf, A.N., and Dick, T.P. (2015). Peroxiredoxin-2 and STAT3 form a redox relay for $\mathrm{H} 2 \mathrm{O} 2$ signaling. Nat. Chem. Biol. 11, 64-70.

Soito, L., Williamson, C., Knutson, S.T., Fetrow, J.S., Poole, L.B., and Nelson, K.J. (2011). PREX: PeroxiRedoxin classification indEX, a database of subfamily assignments across the diverse peroxiredoxin family. Nucleic Acids Res. 39, D332-337.

Storz, G., Jacobson, F.S., Tartaglia, L.A., Morgan, R.W., Silveira, L.A., and Ames, B.N. (1989). An alkyl hydroperoxide reductase induced by oxidative stress in Salmonella typhimurium and Escherichia coli: genetic characterization and cloning of ahp. J. Bacteriol. 171, 2049-2055

Tachibana, T., Okazaki, S., Murayama, A., Naganuma, A., Nomoto, A., and Kuge, S. (2009). A Major Peroxiredoxin-induced Activation of Yap1 Transcription Factor Is Mediated by Reduction-sensitive Disulfide Bonds and Reveals a Low Level of
Transcriptional Activation. J. Biol. Chem. 284, 4464-4472.

Tanaka, T., Izawa, S., and Inoue, Y. (2005). GPX2, encoding a phospholipid hydroperoxide glutathione peroxidase homologue, codes for an atypical 2-Cys peroxiredoxin in Saccharomyces cerevisiae. J. Biol. Chem. 280, 42078-42087.

Tang, H.M., Siu, K.L., Wong, C.M., and Jin, D.Y. (2009). Loss of yeast peroxiredoxin Tsa1p induces genome instability through activation of the DNA damage checkpoint and elevation of dNTP levels. PLoS Genet. 5, e1000697.

Teixeira, F., Castro, H., Cruz, T., Tse, E., Koldewey, P., Southworth, D.R., Tomas, A.M., and Jakob, U. (2015). Mitochondrial peroxiredoxin functions as crucial chaperone reservoir in Leishmania infantum. Proc. Natl. Acad. Sci. USA 112, E616-624

Toledano, M.B., Delaunay, A., Monceau, L., and Tacnet, F. (2004). Microbial $\mathrm{H} 2 \mathrm{O} 2$ sensors as archetypical redox signaling modules. Trends Biochem. Sci. 29, 351-357.

Trujillo, M., Ferrer-Sueta, G., Thomson, L., Flohe, L., and Radi, R. (2007). Kinetics of peroxiredoxins and their role in the decomposition of peroxynitrite. Subcell Biochem. 44, 83-113.

Veal, E.A., Ross, S.J., Malakasi, P., Peacock, E., and Morgan, B.A (2003). Ybp1 is required for the hydrogen peroxide-induced oxidation of the Yap1 transcription factor. J. Biol. Chem. 278, 30896-30904.

Veal, E.A., Findlay, V.J., Day, A.M., Bozonet, S.M., Evans, J.M., Quinn, J., and Morgan, B.A. (2004). A 2-Cys peroxiredoxin regulates peroxide-induced oxidation and activation of a stressactivated MAP kinase. Mol. Cell 15, 129-139.

Vivancos, A.P., Castillo, E.A., Biteau, B., Nicot, C., Ayte, J. Toledano, M.B., and Hidalgo, E. (2005). A cysteine-sulfinic acid in peroxiredoxin regulates $\mathrm{H} 2 \mathrm{O} 2$-sensing by the antioxidant Pap1 pathway. Proc. Natl. Acad. Sci. USA 102, 8875-8880.

Weids, A.J., and Grant, C.M. (2014). The yeast peroxiredoxin Tsa1 protects against protein-aggregate-induced oxidative stress. J. Cell Sci. 127, 1327-1335.

Wong, C.M., Siu, K.L., and Jin, D.Y. (2004). Peroxiredoxin-null yeast cells are hypersensitive to oxidative stress and are genomically unstable. J. Biol. Chem. 279, 23207-23213.

Woo, H.A., Chae, H.Z., Hwang, S.C., Yang, K.S., Kang, S.W., Kim K., and Rhee, S.G. (2003). Reversing the inactivation of peroxiredoxins caused by cysteine sulfinic acid formation. Science 300, 653-656.

Wood, Z.A., Poole, L.B., Hantgan, R.R., and Karplus, P.A. (2002). Dimers to doughnuts: redox-sensitive oligomerization of 2 cysteine peroxiredoxins. Biochemistry 41, 5493-5504.

Wood, Z.A., Poole, L.B., and Karplus, P.A. (2003). Peroxiredoxin evolution and the regulation of hydrogen peroxide signaling Science 300, 650-653.

Wu, C.Y., Bird, A.J., Winge, D.R., and Eide, D.J. (2007). Regulation of the yeast TSA1 peroxiredoxin by ZAP1 is an adaptive response to the oxidative stress of zinc deficiency. J. Biol. Chem 282, 2184-2195.

Yang, K.S., Kang, S.W., Woo, H.A., Hwang, S.C., Chae, H.Z., Kim K., and Rhee, S.G. (2002). Inactivation of human peroxiredoxin I during catalysis as the result of the oxidation of the catalytic site cysteine to cysteine-sulfinic acid. J. Biol. Chem. 277, 3802938036 . 